\title{
A Seven Year-Using Single Hemodialysis Catheter without Complication
}

\author{
Kyung Min Kim ${ }^{\mathrm{a}}$ Soon Kil Kwon ${ }^{\mathrm{b}}$ Sun Moon Kim ${ }^{\mathrm{b}}$ Hye-Young Kim ${ }^{\mathrm{b}}$

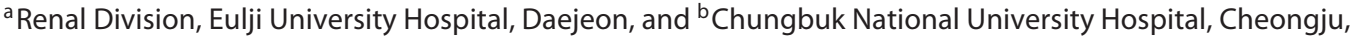 \\ South Korea
}

Dear Editor,

Tunneled cuffed catheters serve as bridging devices during the maturation of newly placed arteriovenous fistulas (AVF) or their use is the final option in patients in whom fistulas or grafts have failed [1]. Although catheters are used in approximately $80 \%$ of patients undergoing incident hemodialysis (HD), tunneled cuffed catheters are known to result in complications including catheter-related bacteremia and central vein thrombosis [2]. Thus, catheters should be removed when AVF is available. However, catheters are occasionally used as a permanent vascular access, particularly in cases where alternative options are limited [3]. Although there are reports that show prolonged $\mathrm{HD}$ catheter for more than 5 years $[4,5]$, how long catheters should be used when they are maintained as a permanent vascular access remains unknown. In our clinic, we continue to care for a patient with a tunneled cuffed catheter that has been used for 7 years without complications. This study was approved by the institutional review board and we obtained the patient's informed consent.

A 54-year-old man has been undergoing HD due to hypertensive end-stage renal disease since 2004. After 6 years' use, the AVF became occluded and a tunneled cuffed catheter was inserted to bridge a subsequent AVF. However, the patient refused the new AVF and all other medications except erythropoietin. For the past 7 years, the catheter insertion site has remained clear without erythema or cuff exposure. Povidone-iodine was used for exit-site protection, and routine heparin was locked after HD. Urokinase locking was used for 1-6 months in 2010, 2011, and 2013 when arterial blood flow was

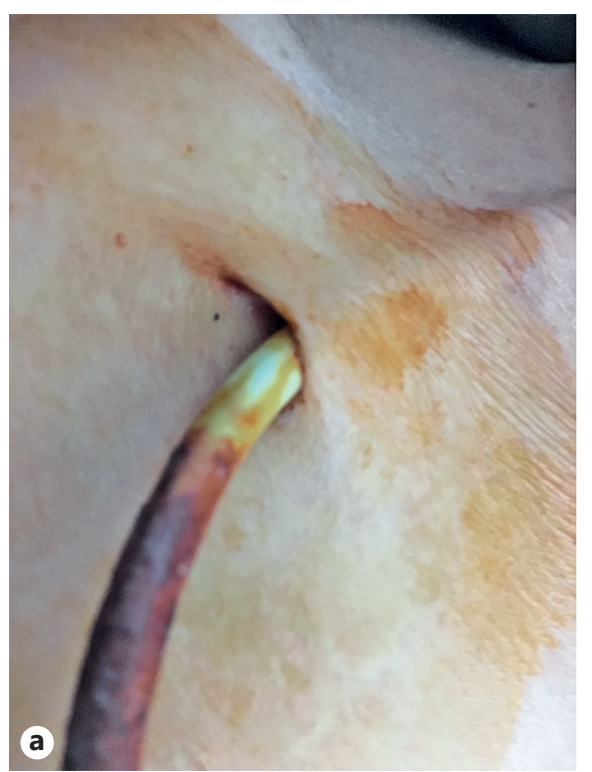

Fig. 1. a The catheter is not damaged physically, and the exit site is clear. b Although the arterial and venous lines are compressed by repeated clamping, the blood flow is still 250 $\mathrm{mL} / \mathrm{min}$.

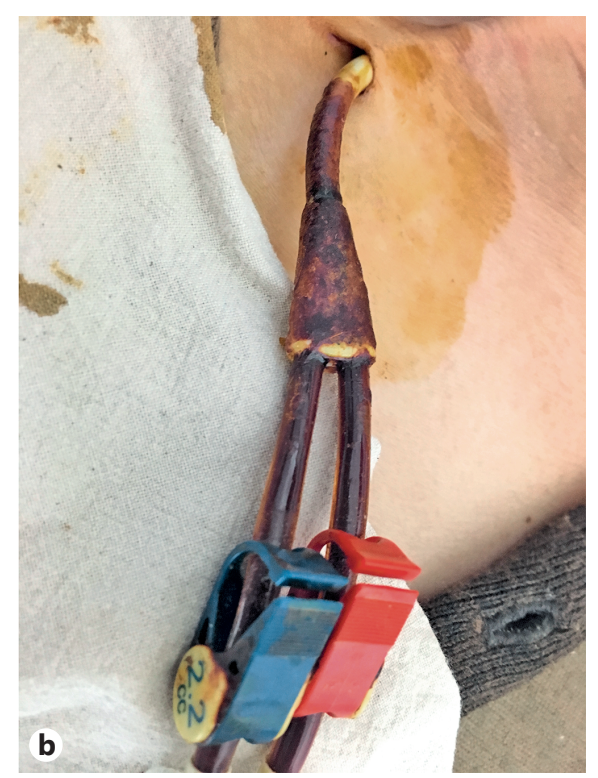

decreased. However, there was no thrombus, nor occlusion for last 7 years. Although the catheter is covered with a brown layer associated with mixed cotton fibers on dried povidone due to repeated dressing, the catheter has not been defective or physically damaged (Fig. 1a). Arte-
๑) 2017 S. Karger AG, Basel
Soon Kil Kwon, MD, PhD

Department of Internal Medicine

Chungbuk National University Hospital, 1 Soonwhanro (St.)

Seowon-gu, Cheongju 361-763 (South Korea)

E-Mail kwon@chungbuk.ac.kr 
rial and venous lines were compressed by repeated clamping; however, the blood flow remained at $250 \mathrm{~mL} / \mathrm{min}$ for the last 4 years (Fig. 1b). The patient is undergoing maintenance HD 3 times per week for $3 \mathrm{~h}$ each with stable laboratory findings and average weekly $\mathrm{Kt} / \mathrm{V}$ of $>1.40$ without any single catheter-related bacteremia and complication. Removal of the cathe- ter will now be complicated due to vascular adhesion [6]; thus, the current cuffed catheter will be used for lifelong HD.

This report details the long-term use of a dual-lumen catheter secondary to poor patient compliance. Long-term use of a tunneled cuffed catheter should be avoided due to catheter-related complications; however, if managed and maintained carefully, the catheter could continue to be used over a much longer term.

\section{Disclosure Statement}

All the authors have declared no competing interest.

\section{References}

1 Karkar A, Chaballout A, Ibrahim MH, Abdelrahman M, Al Shubaili M: Improving arteriovenous fistula rate: effect on hemodialysis quality. Hemodial Int 2014; 18: 516-521.

2 Danese MD, Liu Z, Griffiths RI, Dylan M, Yu HT, Dubois R, et al: Catheter use is high even among hemodialysis patients with a fistula or graft. Kidney Int 2006;70:1482-1485.

3 Quarello F, Forneris G, Borca M, Pozzato M: Do central venous catheters have advantages over arteriovenous fistulas or grafts? J Nephrol 2006; 19:265-279.

4 Canaud B, Leray-Moragues H, Garrigues V, Mion C: Permanent twin catheter: a vascular access option of choice for haemodialysis in elderly patients. Nephrol Dial Transplant 1998;13(suppl 7):82-88.
5 Lemaire $\mathrm{X}$, Morena $\mathrm{M}$, Leray-Moragués H, Henriet-Viprey D, Chenine L, DefezFougeron C, Canaud B: Analysis of risk factors for catheter-related bacteremia in 2000 permanent dual catheters for hemodialysis. Blood Purif 2009;28:2128.

6 Tan EK, Tan SG: The permanent catheter. Hemodial Int 2014;18:522-524. 